\title{
WAAM TECHNOLOGY OPTIMIZED BY OFF-LINE 3D ROBOT SIMULATION
}

\author{
TOMÁŠ GurČÍK*， KAREL KovandA
}

\author{
Czech Technical University in Prague, Faculty of Mechanical Engineering, Department of Manufacturing \\ Technology, Technická 4, 166 07 Praha 6, Czech Republic \\ * corresponding author: tomas.gurcik@fs.cvut.cz
}

\begin{abstract}
WAAM (Wire + Arc Additive Manufacturing) is an alternative additive technology that combines an electric arc as a heat source, filler material in the form of a wire for welding and cladding individual weld passes so as to ultimately achieve the closest shape of produced components. Nowadays, when it is modern to digitize the manufacturing production, this process can also be designed using off-line programming tools and 3D simulations of the robot that welds the whole structure. This study deals with the comparison of three structured continuous welds using different weld metal transfers. From the results of the first two processes (dip transfer and IAC process), optimization was achieved using the CMT process and the welding path correction. As the filler material, the low-alloyed solid wire electrode for shielded arc welding of quenched and tempered fine grained structural steels, Böhler Union X 90 (G $896 \mathrm{M} \mathrm{Mn4Ni2CrMo)} \mathrm{with} 1 \mathrm{~mm}$ in diameter, was used. Obtained samples were subjected to standard technological tests. The results of these tests are used to determine new parameters to ensure stability of this technology. The experiment confirmed that off-line programming will greatly influence the speed and quality of the welding track programs. The results prove that, by combining off-line welding path optimization with an optimized CMT welding process, we can achieve a stable WAAM process.
\end{abstract}

KEYWORDS: WAAM, robotic welding, off-line programming, FANUC ROBOGUIDE, CMT.

\section{INTRODUCTION}

According to the International Federation of Robotics (IFR) annual report from 2017, presented at a press conference in Frankfurt am Main, more than 3 million industrial robots will be installed in manufacturing plants around the world by 2020 . With the number of units installed in the world rising from 2017 to 2020 by as much as $14 \%$. This rising tendency may not be only a response to the problem of companies getting qualified workers, or tendency of the future to automate small and medium-sized factories by Industry 4.0 concepts, but also for example, the use of robotics for new technologies. [1]

One of these technologies can also be the additive production used on robotic workplaces, using the currently applied devices - the welding source and the robot. This alternative additive manufacturing technology is WAAM (Wire + Arc Additive Manufacturing). Together with the available software tools such as off-line robot simulators, this process can be applied in the future in a real-time production and concurrently to replace non-economic manufacturing processes for specific machine components.

The objective of this study is to experimentally verify main parameters describing the behaviour of this technology. The welding process was carried out using the dip metal transfer and modified dip metal transfer (IAC) and it was monitored by the WeldMonitor measuring device during the whole cladding time. As the filler material, a low-alloyed solid wire electrode for shielded arc welding of quenched and tempered fine grained structural steels under the brand name Union X 90 (G $896 \mathrm{M}$ Mn4Ni2CrMo) was used. The obtained data will serve to optimize and establish new parameters for a further WAAM research.

\section{WAAM TECHNOLOGY}

Additive manufacturing is currently one of the fastest emerging manufacturing technologies. It's used for the production of prototypes or entire machine components. The principle of additive production is the placement of individual layers of a particular material so that in the resultin order to we get the shape that is as close as possible to its CAD template. Unlike during conventional production technologies, there is a significantly lesser amount of waste material because the input material is not a full profile. 2]

As a classical additive technology in manufacturing, we consider 3D printing or otherwise SLS (Selective Laser Sintering), when the laser beam sinters aed material that is in powder form to a layer with a thickness of about $0.1 \mathrm{~mm}$. The WAAM technology is considered an alternative additive technology as it is based on the classic SLS principle, but its investment and operational demands are more favourable. [3]

The WAAM was developed at Cranfield University. Its first mention dates back to the 1960s, although the first patent was introduced in 1925. For its implementation, a classical robotic welding equipment is currently used - a multi-axis robot or portal machine, 


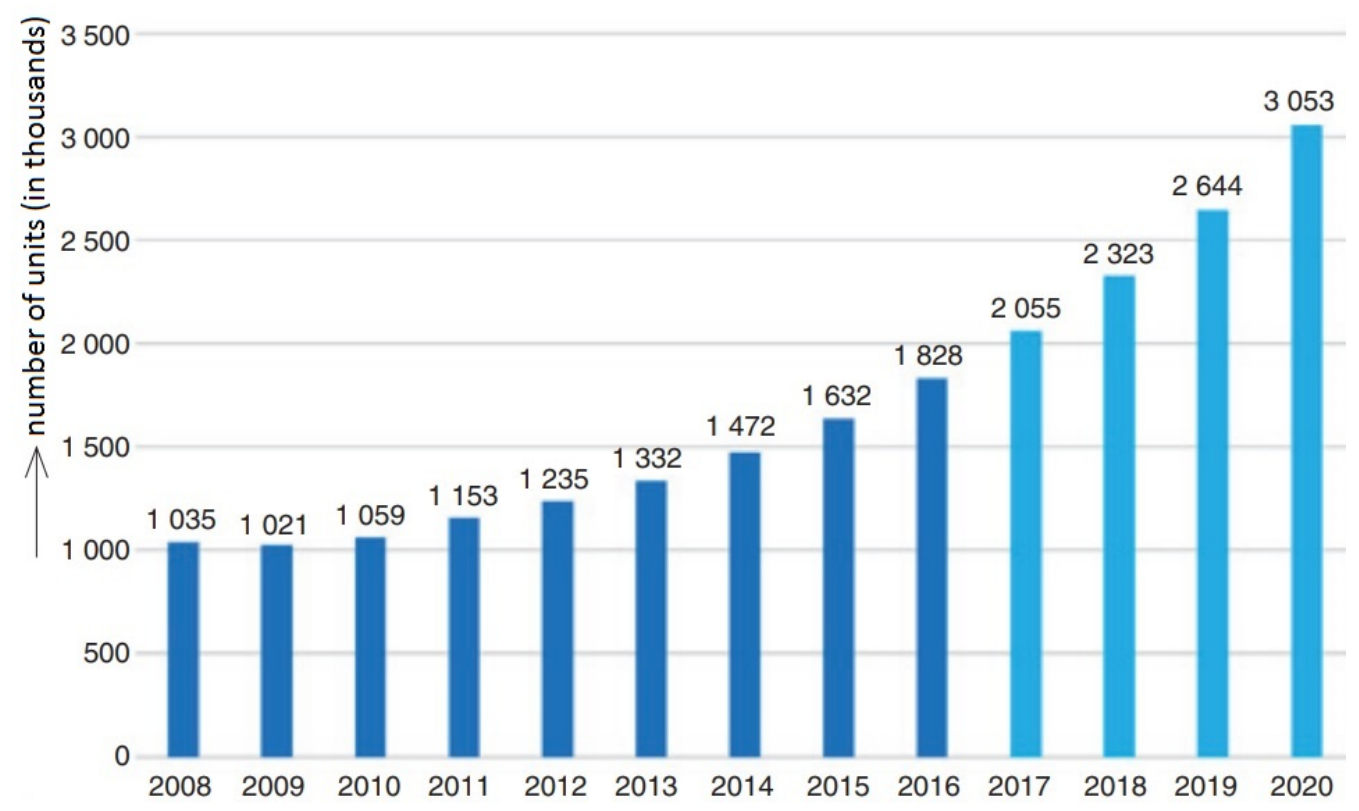

FiguRE 1. The number of installed robots (in thousands) in the world by 2016 and the assumption of growth to 2020 [1].

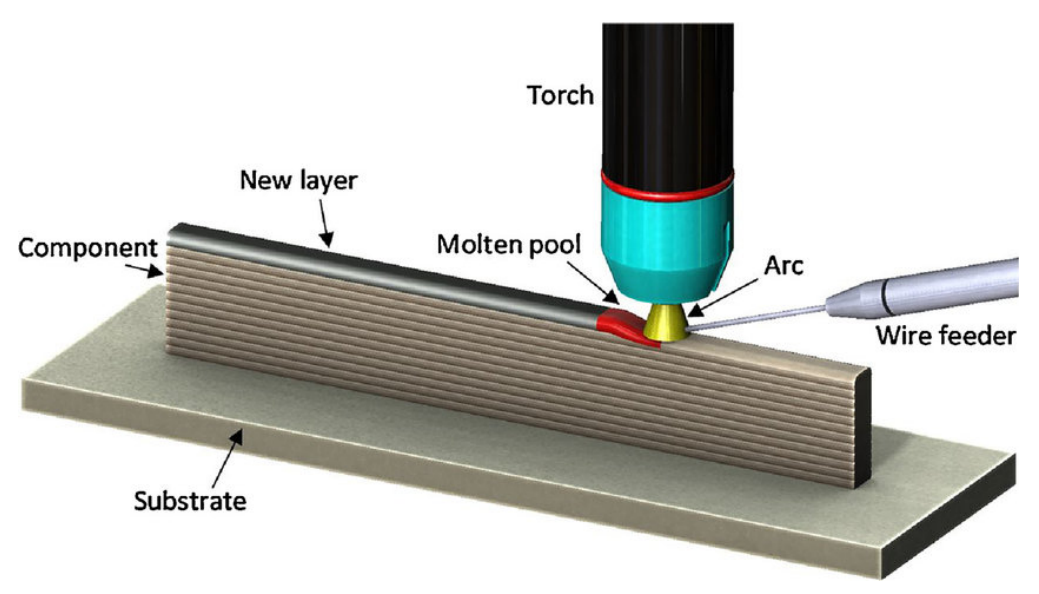

FigURE 2. Illustration of the WAAM process using TIG technology [4.

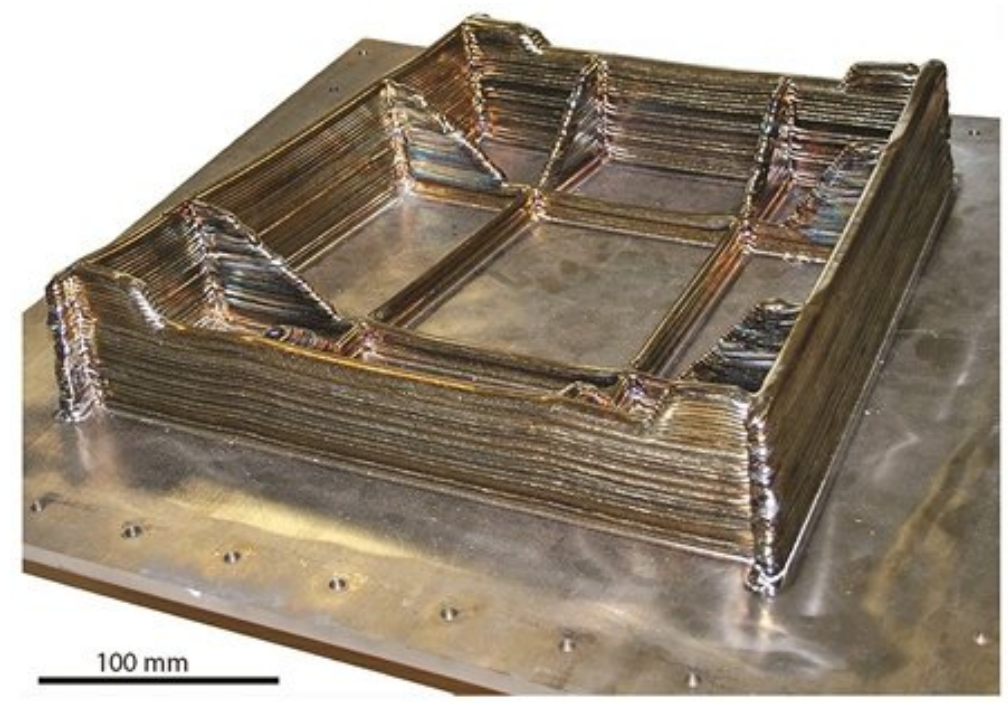

Figure 3. Part of the Bombardier chassis made of titanium alloy using WAAM technology [2]. 


\begin{tabular}{lcccc}
\hline Technology & Input material weight & Final part weight & BTF & Waste \\
\hline Milling & $240 \mathrm{~kg}$ & $21 \mathrm{~kg}$ & 11.4 & $91 \%$ \\
WAAM & $24 \mathrm{~kg}$ & $21 \mathrm{~kg}$ & 1.14 & $13 \%$ \\
\hline
\end{tabular}

TABLE 1. Comparison of the material ratios for manufacturing the part of Figure 3 [2].

a current welding power source, welding torches and wire feed systems. The heat source is an electric arc, the filler material is used in the form of a wire, which is supplied on spools or high-capacity barrel packages. During the process, individual welding passes are created as shown in Figure 2. Their layering paths are programmed into the robot controller. Currently, the development of the WAAM is directed to its use in the aerospace industry, due to the increasingly demanding requirements for reducing the amount of waste in the production of aviation components make it necessary to replace the current production processes of bulky structures. The benchmark for this optimization is the BTF (Buy-to-Fly ratio), which focuses on the volume ratio of the input material to the output, which is currently in the range of $10 \div 20: 1$. With this alternative additive technology, it is expected to reduce this ratio by $35-45 \%$ and in the result, reduce the weight of the aircraft by $30 \%$ and its price even by $60 \%$. Figure 3 and Table 1 are examples of these assumptions. 2, 5, 6]

\section{OfF-Line SIMUlator}

As already mentioned, the current tendency to digitize the production brings the increasing use of software solutions for the pre-production planning. Programs for an off-line 3D motion simulation or application order progressively reduce the time of creating new motion configurations. By default, these programs support a linkage with CAD models so it is possible to design or digitize existing robotic workplaces. Each robot maker has its own program that is compatible with their system environment and a library of products. These simulators serve all types of robots with their specific applications, such as automatic deburring, product handling, component coating, palletizing and just welding as it can be seen in Figure 4

In these programs, we can control the robot through all its axes. It is also possible to program individual motion installs before they are loaded into the control unit located in the actual workplace. During the on-line programming, it is necessary to create motion instructions in the presence of the operator directly at the workplace. This is only possible with a limited speed of the robot movement and there is a high probability of its collision with the environment during the test run. With the off-line programming, motion instructions are made significantly faster, preliminary simulations reveal potential collisions and increase the lifespan of expensive devices. By using a computer environment, it is also easier, for example, to accu- rately achieve the welding torch's inclination towards the workpiece.

\section{EXPERIMENT}

\subsection{EXPERIMENTAL WORKPLACE}

The main part of the experiment took place in the inter-faculty Laboratory of Welding Technologies situated at Department of Manufacturing Technologies CTU Prague, which has, among other things, a robotic workplace for arc welding. This workplace contains the universal 6-axis FANUC Arc Mate 100iC robot with a maximum reach of $1420 \mathrm{~mm}$ and a repeatability of $\pm 0.08 \mathrm{~mm}$ and its R-J3iC control unit. There is also a one-axis positioner FANUC P250, welding source for MIG/MAG and TIG welding, with additional wire feeders from Migatronic with a welding wire and protective gas cylinders. Of course, the workplace has central exhausting and safety features, such as light barriers preventing the entry into the workspace and door switches preventing a person entering the operating area.

\subsection{VirTUAL WORKPLACE}

For a full use of the virtual workstation, it is necessary to make a real calibration with it. For the current workplace, the already created model by Ing. Pavel Pres, who used it to solve his project (Robotic welding bridge handrail by method GMAW, 2013), was used. However, it was necessary to recalibrate the workplace and add and modify a part of the components for a correct functionality in the virtual workplace. A view on the virtual and real preparation of the experiment in Figure 5 and Figure 6 .

When describing off-line simulators, it was already mentioned that they are most often used for the preprogram creation. This experiment used the reverse procedure. The program written by on-line programming was imported into the simulator to carry out the inspection. During this review, the Tool Center Point (TCP) mapping found that the start and end positions of the circular path did not match as it can be seen in Figure 7 and Figure 8. This means that defects can occur at this point, where the welding torch is lifted by a one-height step. The corrected program has been simulated and then exported back to the robot controller to start it as it can be seen in Figure 9 and Figure 10

The main problem is that the whole circle must be programmed with two semicircles. Although it is possible to enter the start and end points in the same place with the on-line programming, it is often 

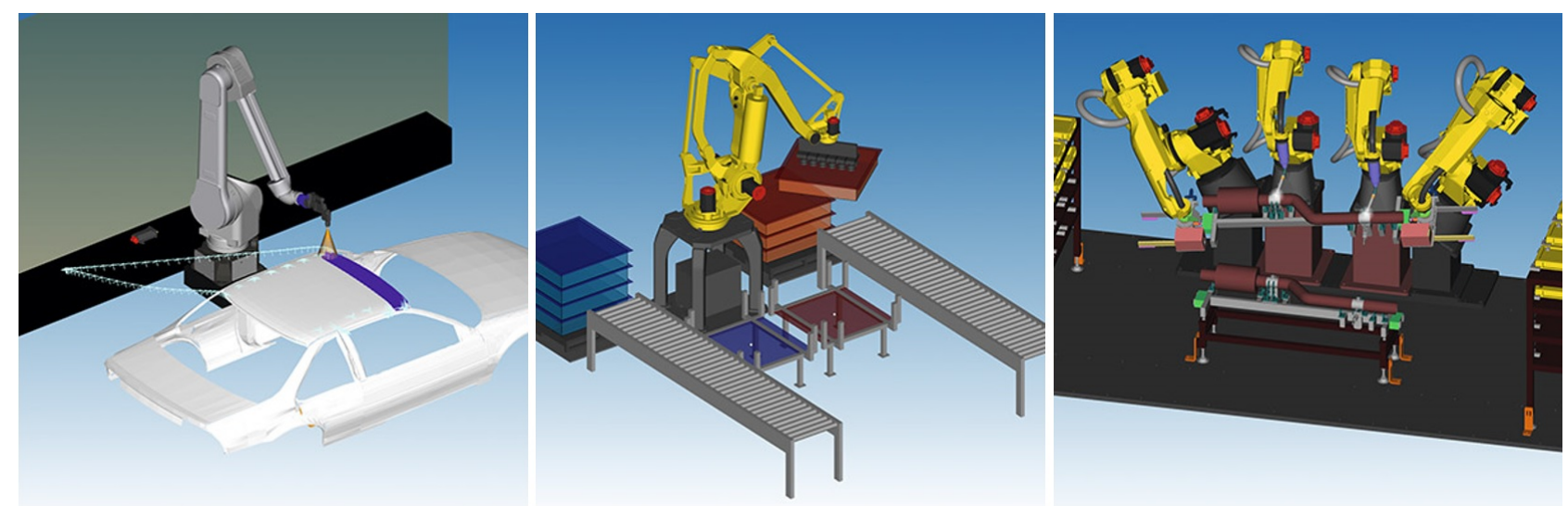

FigURE 4. Examples of off-line simulations in FANUC ROBOGUIDE software. From the right component coating, palletizing and welding [7].

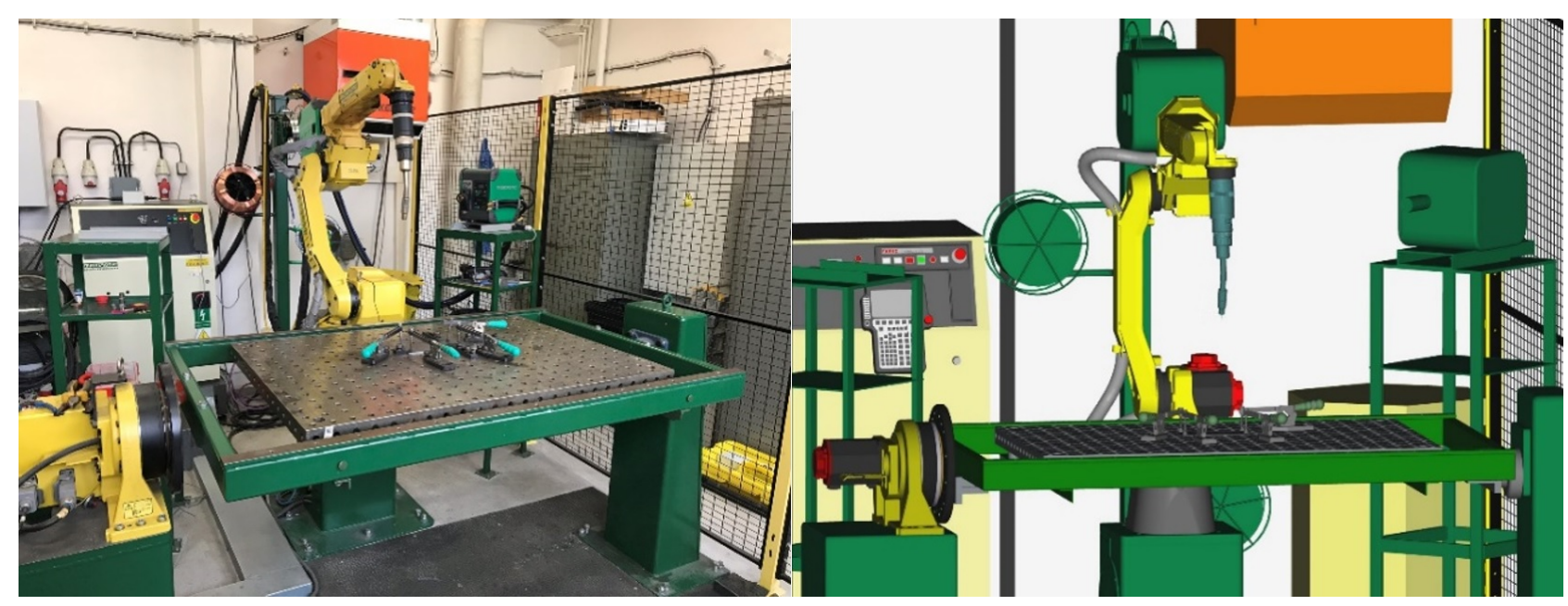

FIGURE 5. View of the real workplace (left), view of the workplace in the FANUC ROBOGUIDE simulator (right).

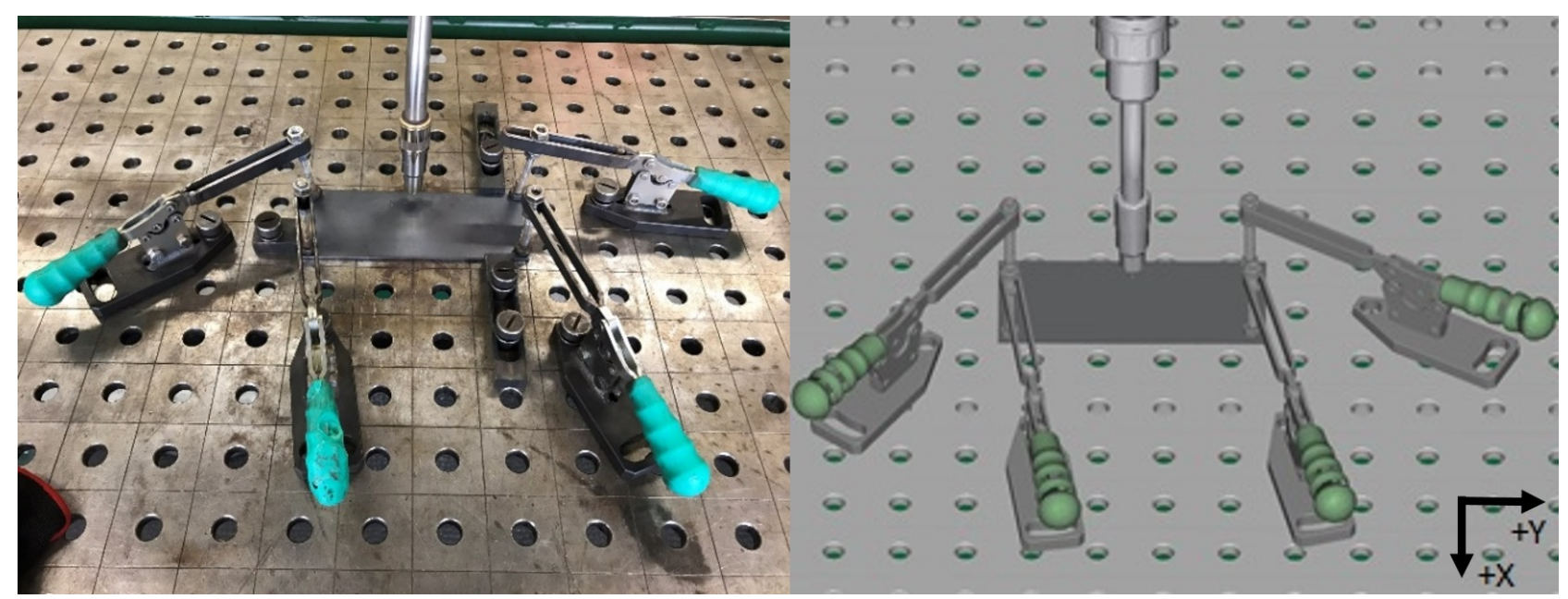

FigurE 6. View of the base plate mounting on the welding table (right), realization in the laboratory (left). 


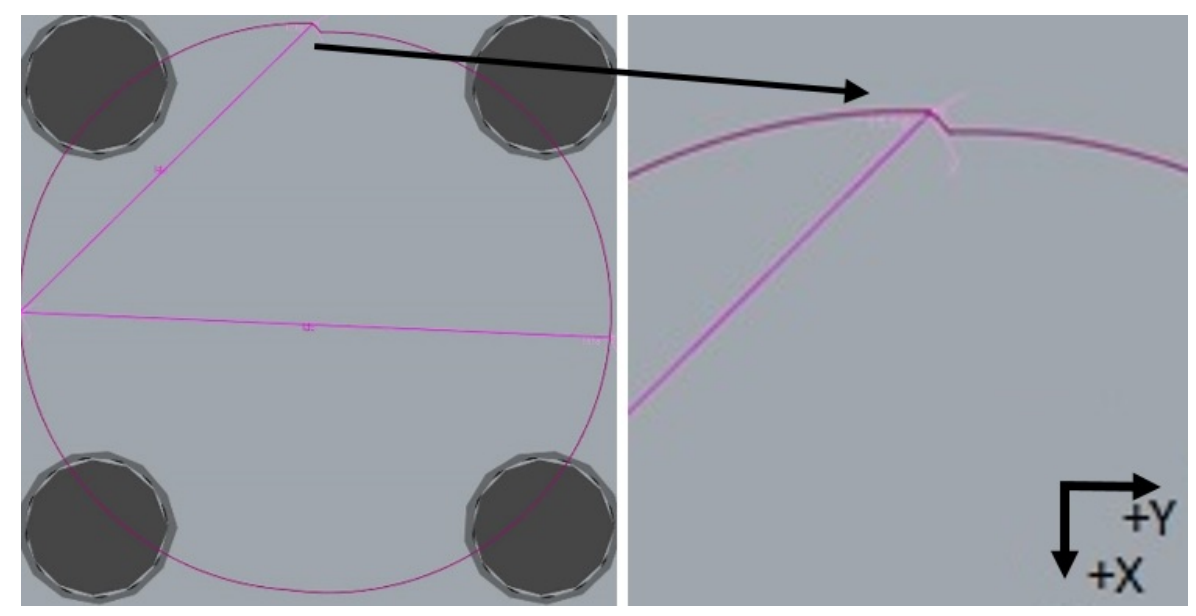

FIGURE 7. Incorrectly created start and end points from on-line programming.
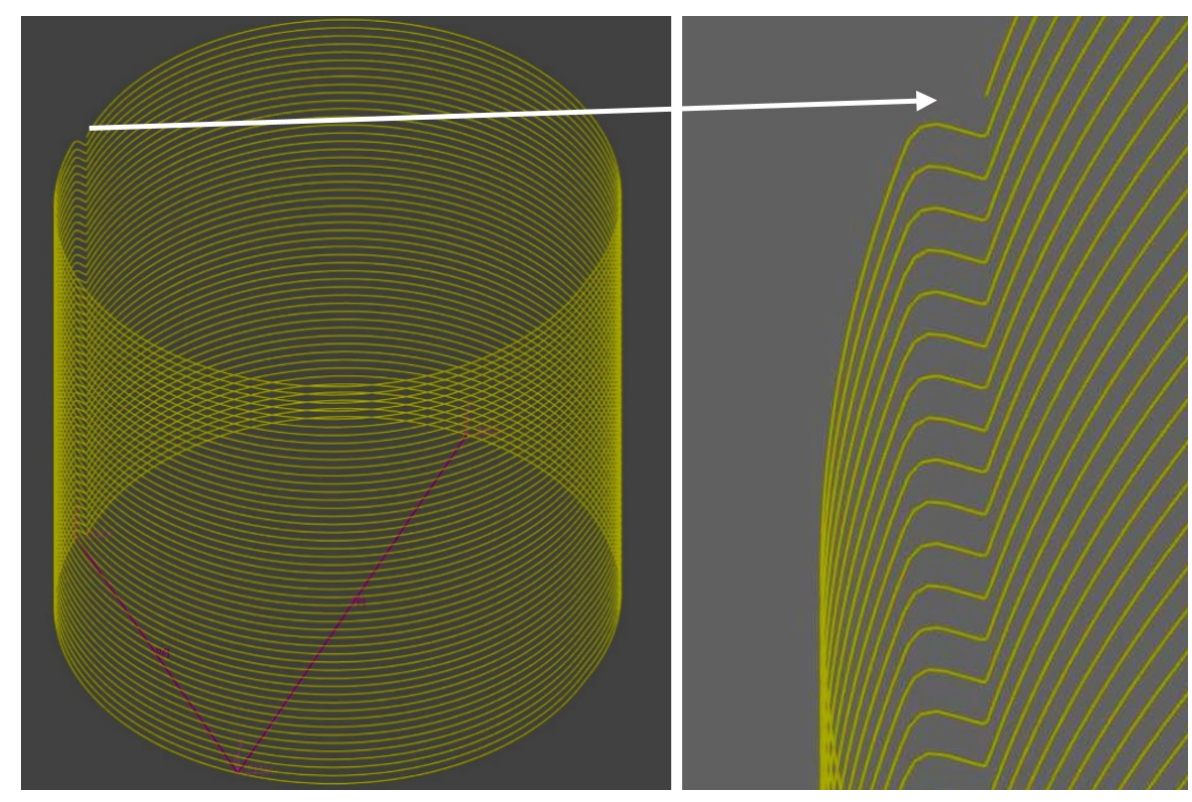

Figure 8. View of the base plate mounting on the welding table (right), realization in the laboratory (left).

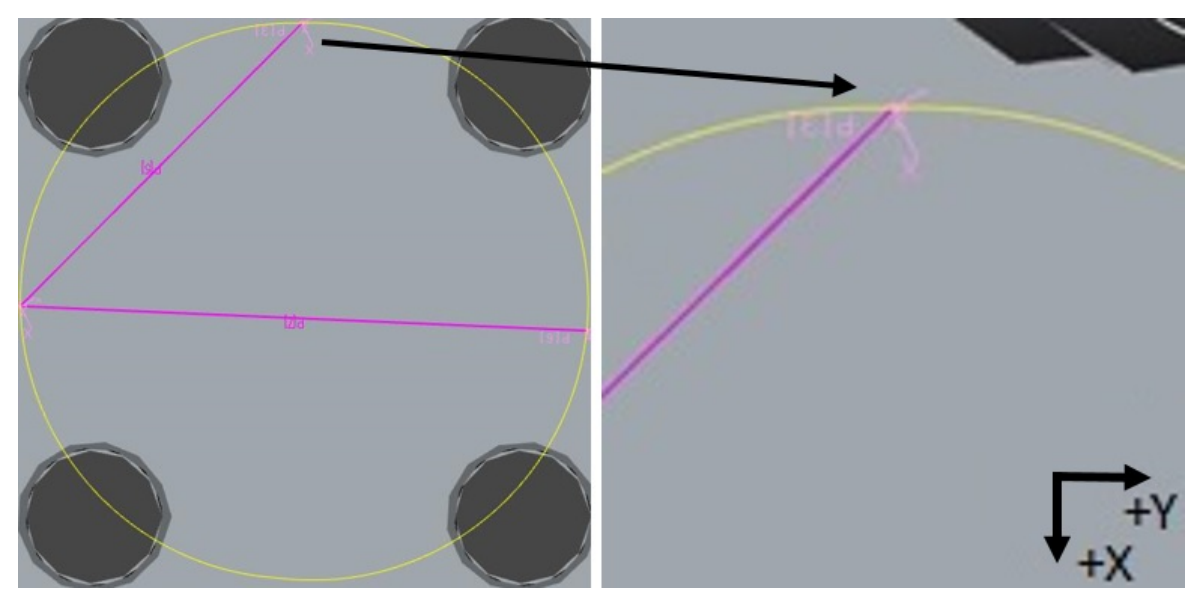

FiguRE 9. Fixed robot track using off-line programming. 

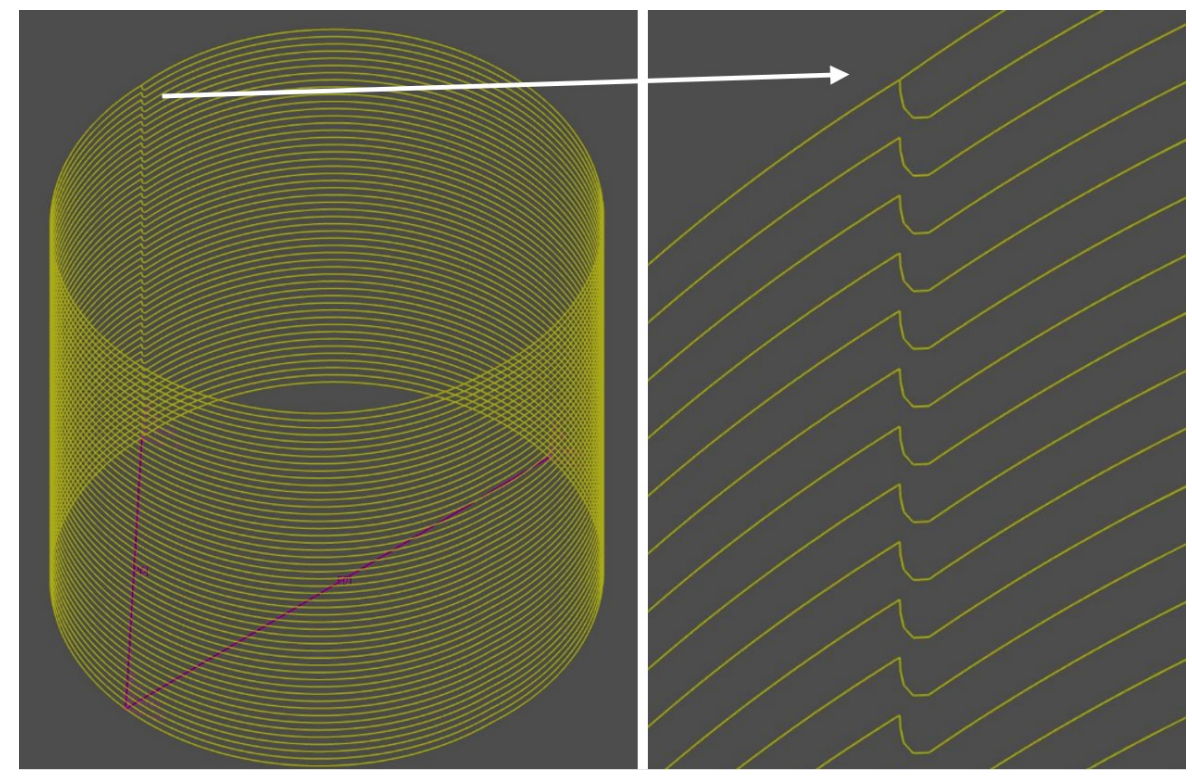

FiguRE 10. Drawing of paths of program which was used in this research.

\begin{tabular}{cccc}
\hline $\begin{array}{c}R_{m} \\
{\left[\mathrm{~N} / \mathrm{mm}^{2}\right]}\end{array}$ & $\begin{array}{c}R_{e} \\
{\left[\mathrm{~N} / \mathrm{mm}^{2}\right]}\end{array}$ & $\begin{array}{c}A_{5} \\
{[\%]}\end{array}$ & $\begin{array}{c}K_{v} \\
{[\mathrm{~J}]}\end{array}$ \\
\hline 950 & 890 & 15 & 90 \\
\hline
\end{tabular}

TABlE 2. Mechanical properties of Union X 90 wire at room temperature 8 .

\begin{tabular}{cccccc}
\hline $\mathrm{C}$ & $\mathrm{Si}$ & $\mathrm{Mn}$ & $\mathrm{Cr}$ & $\mathrm{Mo}$ & $\mathrm{Ni}$ \\
\hline 0.1 & 0.8 & 1.8 & 0.35 & 0.6 & 2.3 \\
\hline
\end{tabular}

TABle 3. Chemical composition of Union X 90 wire in weight $\%$.

possible to create an error while writing this script. Even a small deviation can cause significant geometric inaccuracies. In this case, the coefficient of effective wall thickness will be reduced at this point.

\subsection{INPUT DATA FOR EXPERIMENT}

As the filler material, the low-alloyed solid wire electrode for shielded arc welding of quenched and tempered fine grained structural steels was used - a $1 \mathrm{~mm}$ diameter Böhler Union X 90 according to ČSN EN ISO 16834 marked G $896 \mathrm{M}$ Mn4Ni2CrMo with the properties mentioned in Table 2 and Table 3

Other parameters were wire feeding speed $2.4 \mathrm{~m} / \mathrm{min}$, protective gas M21 (82\% Ar, $18 \% \mathrm{CO} 2)$, welding torch feed rate $30 \mathrm{~cm} / \mathrm{min}$. The entire program was set to 50 cycles (layers) with constant torch lifting after one cycle by $1.2 \mathrm{~mm}$. The parameter of torch lifting was chosen according to previous experiments that did not use stick out sensors. A part of the experiment is also a comparison of the two different types of weld metal transfers used - dip metal transfer and modified dip metal transfer under the brand name
IAC (Intelligent Arc Control) available on Migatronic welding sources.

The modified dip transfer IAC has the task of reducing the heat-affected area, increasing the welding speed and reducing the spatter. The IAC is characterized by a higher intensity of the welding current at the time of the dripping metal particle. However, the higher dip current would cause an even greater spatter during the unchanged dip times. The IAC is typical for shortening the duration of the dip current compared to the conventional GMAW process.

\section{EXPERIMENT EVALUATION}

\subsection{Visual eVALUation}

In Figure 11 wa can observe regular, visually and geometrically opaque individual layers of approximately $20 \mathrm{~mm}$ on both samples. This can be caused by a too high heat input.

\subsection{Output From WeldMonitor}

The main reason of the measurement was to obtain data that characterize the entire welding cycle and to monitor their fluctuating behaviour. Thus, it was possible to identify values that have a significant impact on the final quality of the welds. These values are welding voltage, welding current and wire feeding speed, which has a major impact on the consumption of the filler material. A parameter listing with a scanning frequency of 60 seconds was taken for an tentative assessment. These data were divided into 5 parts, which represent the height part of the structured weld. This means that part 1 is $1 / 5$ of the height of the structured weld from its initial welding point. These data for each part of the weld height were averaged in Table 4

The voltage values can be considered constant. The welding current values drop slightly in the dip trans- 


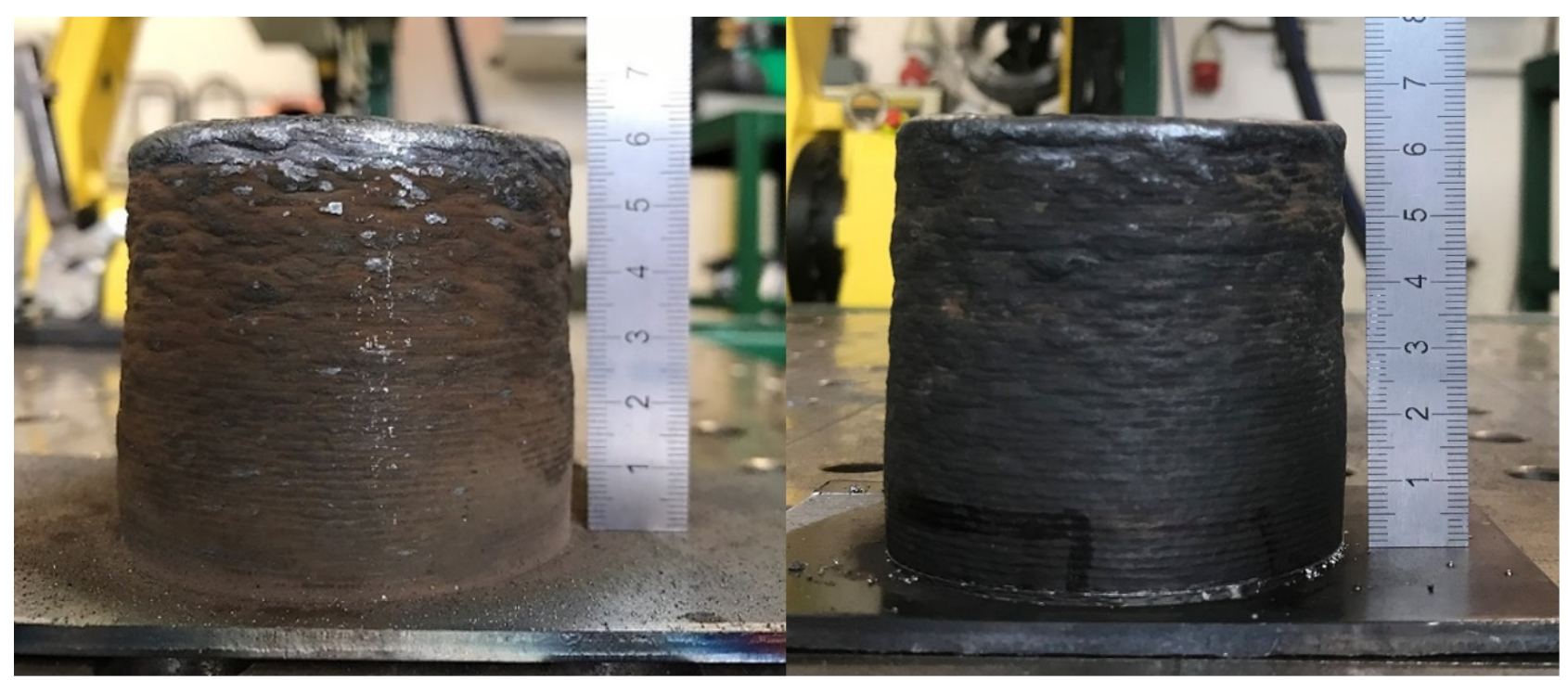

FiguRE 11. Structured surfacing created by dip metal transfer (left). Structured surfacing created by IAC process (right).

\begin{tabular}{cccccc}
\hline \multirow{2}{*}{ Process } & \multicolumn{5}{c}{ Part } \\
\cline { 2 - 5 } & 1 & 2 & 3 & 4 & 5 \\
\hline \multirow{5}{c}{ Voltage [V] } \\
Dip transfer & 20.4 & 20.3 & 20.4 & 20.5 & 20.5 \\
IAC & 20.3 & 20.2 & 20.3 & 20.3 & 20.3 \\
\hline \multicolumn{5}{c}{ Current [A] } \\
Dip transfer & 77.8 & 78.9 & 77.3 & 76.9 & 76.3 \\
IAC & 83.7 & 85.1 & 85.9 & 83.7 & 87.9 \\
\hline & Wire feeding speed [m/min] \\
Dip transfer & 2.4 & 2.4 & 2.4 & 2.4 & 2.4 \\
IAC & 2.4 & 2.4 & 2.5 & 2.3 & 2.4 \\
\hline
\end{tabular}

TABLE 4. Average values in individual parts of the WAAM process.

fer. However, the IAC process increases up to the deviations of the average values of the fourth part, but it is again increasing in character as a response to the change in the size of the welding wire extension.

\subsection{EWT AND SW PARAMETERS}

The EWT (Effective Wall Thickness) and SW (Surface Waviness) parameters are the main criteria for evaluating the geometric stability of the welds.

As shown in the Figure 12, the SW values for the dip transfer are greater than $1 \mathrm{~mm}$ on the inner and outer walls of the sample. For the IAC process sample, the SW value is less than $1 \mathrm{~mm}$ on the outer wall only. A SW value reaching a maximum of $1 \mathrm{~mm}$ can be considered a stability criterion. The height of both samples is not the same because they were cut off at a different distance from the base plate.

From the results of the first two samples (dip transfer and IAC process), it is evident that, by reducing the heat input, it is possible to achieve a higher quality weld surface. This is the reason for the optimization of the WAAMin this experiment by using a special CMT (Cold Metal Transfer) process.

\subsection{Optimization SUgGestion}

A process that is currently capable of a low heat input at the same welding parameters as the dip transfer is the CMT. The length of the welding arc is controlled by the CMT at the speed and duration of the welding wire. This is controlled by mechanical quantities instead of the welding voltage and current. The speed of the transfer of information between the welding source and the wire feeder must be very fast.

The surfacing, in this experiment, was created during the constant high lifting, which took place at the beginning and end of the circular path. Due to this, a higher amount of material is added at this point as it can be seen in Figure 13. Especially during the CMT process, because the moment of the lifting of the welding torch to the next layer causes a change of the welding arc length. The wire feeder responds to this change with a high feeding speed to stabilize welding parameters with a right welding arc length. This problem can be solved by the relationship between the robot movement and the instruction, when the robot should be lifted to the next layer according to motion registers as it can be seen in Figure 14

\subsection{Evaluation of the CMT sample}

The same pre-set parameters as the dip transfer were used.

The main change from previous samples is the height at which the CMT sample appears geometrically stable - up to $35 \mathrm{~mm}$ in height. The use of a "cold" welding process may have an effect on this height, as overheating takes longer than in the previous processes.

The obtained data mentioned in the Table 5 demonstrate the previous description of the CMT technology. 

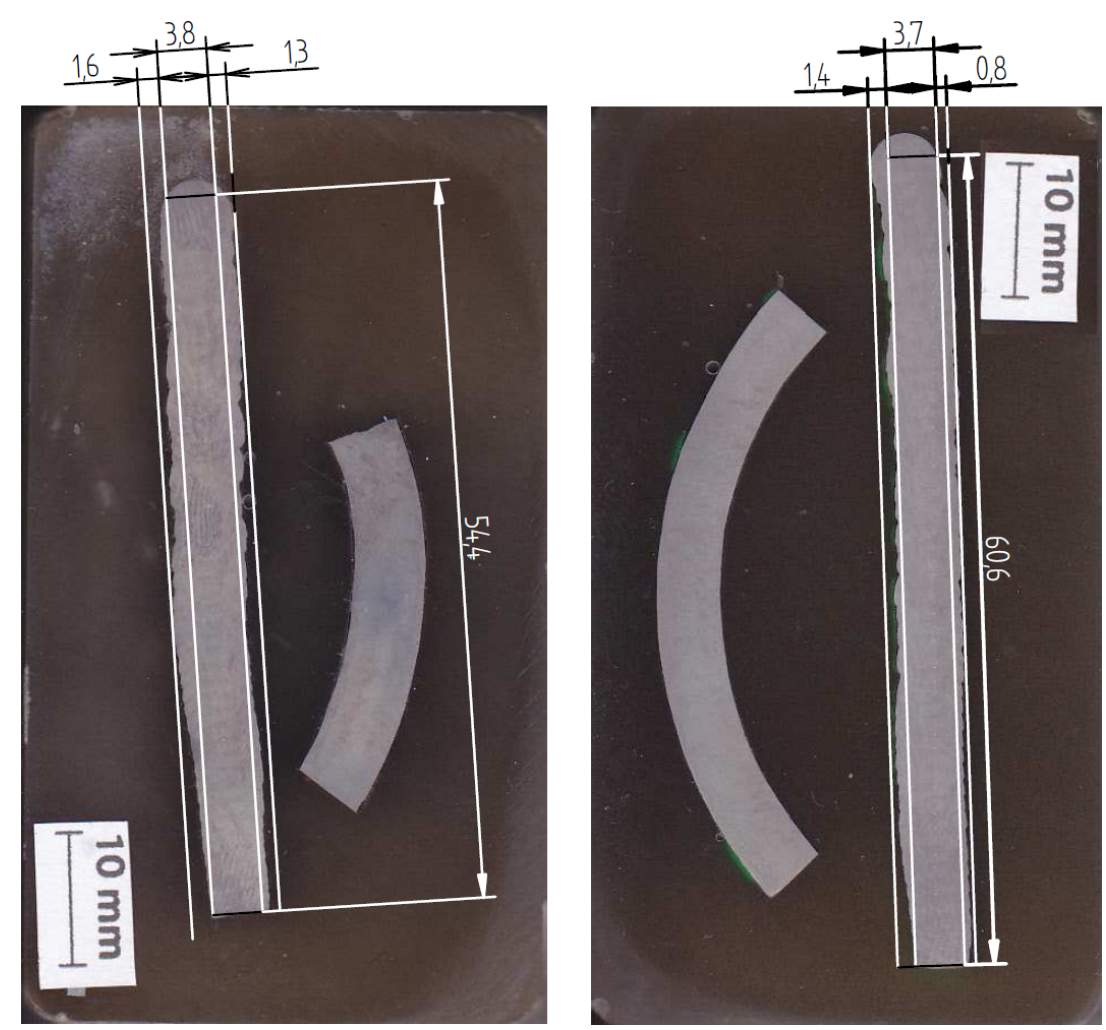

FIGURE 12. EWT and SW parameters for dip metal transfer (left) and IAC process (right).

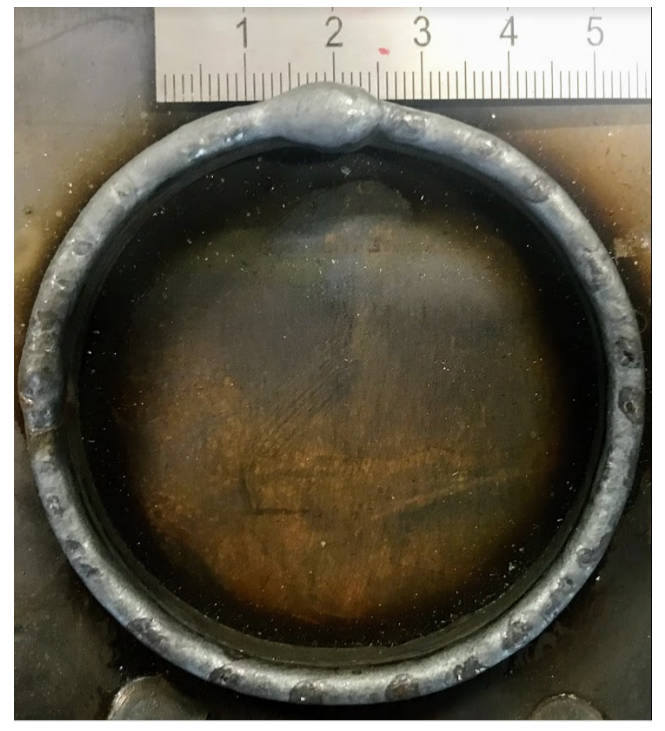

Figure 13. Defects caused by too high wire feeding speed.

While the values of the current and voltage appears constant, the value of the wire feed speed fluctuates. This ensures a small heat input. The releasing of the drop does not occur with a high short-circuit current, but by pulling the drop from the weld pool.

For the parameters, the sample shows a EWT parameter of $4.3 \mathrm{~mm}$ with a $\mathrm{SW}$ parameter $1 \mathrm{~mm}$ on both sides of the sample.

\begin{tabular}{cccccc}
\hline \multirow{2}{*}{ Process } & \multicolumn{5}{c}{ Part } \\
\cline { 2 - 6 } & 1 & 2 & 3 & 4 & 5 \\
\hline & \multicolumn{5}{c}{ Voltage [V] } \\
Dip transfer & 20.4 & 20.3 & 20.4 & 20.5 & 20.5 \\
IAC & 20.3 & 20.2 & 20.3 & 20.3 & 20.3 \\
CMT & 15.7 & 15.7 & 15.8 & 15.6 & 15.7 \\
\hline \multicolumn{5}{c}{ Current [A] } \\
Dip transfer & 77.8 & 78.9 & 77.3 & 76.9 & 76.3 \\
IAC & 83.7 & 85.1 & 85.9 & 83.7 & 87.9 \\
CMT & 91.3 & 91.1 & 91.4 & 91.3 & 91.3 \\
\hline & Wire feeding speed [m/min] \\
Dip transfer & 2.4 & 2.4 & 2.4 & 2.4 & 2.4 \\
IAC & 2.4 & 2.4 & 2.5 & 2.3 & 2.4 \\
CMT & 2.2 & 2.5 & 2.4 & 2.3 & 2.6 \\
\hline
\end{tabular}

TABLE 5. Average values in individual parts of the WAAM process with CMT process.

\section{Conclusion}

The aim of this study was to use off-line programming and find the main parameters to achieve a stable WAAM process. It was demonstrated on a circle path of cladding, programmed in an off-line simulator. This way of creating programs greatly increases the productivity and quality of this technology. It has been proven that this method can also be used as a control tool between on-line and off-line programming using reverse engineering. According to the data obtained by the WeldMonitor measuring set, the heat input 

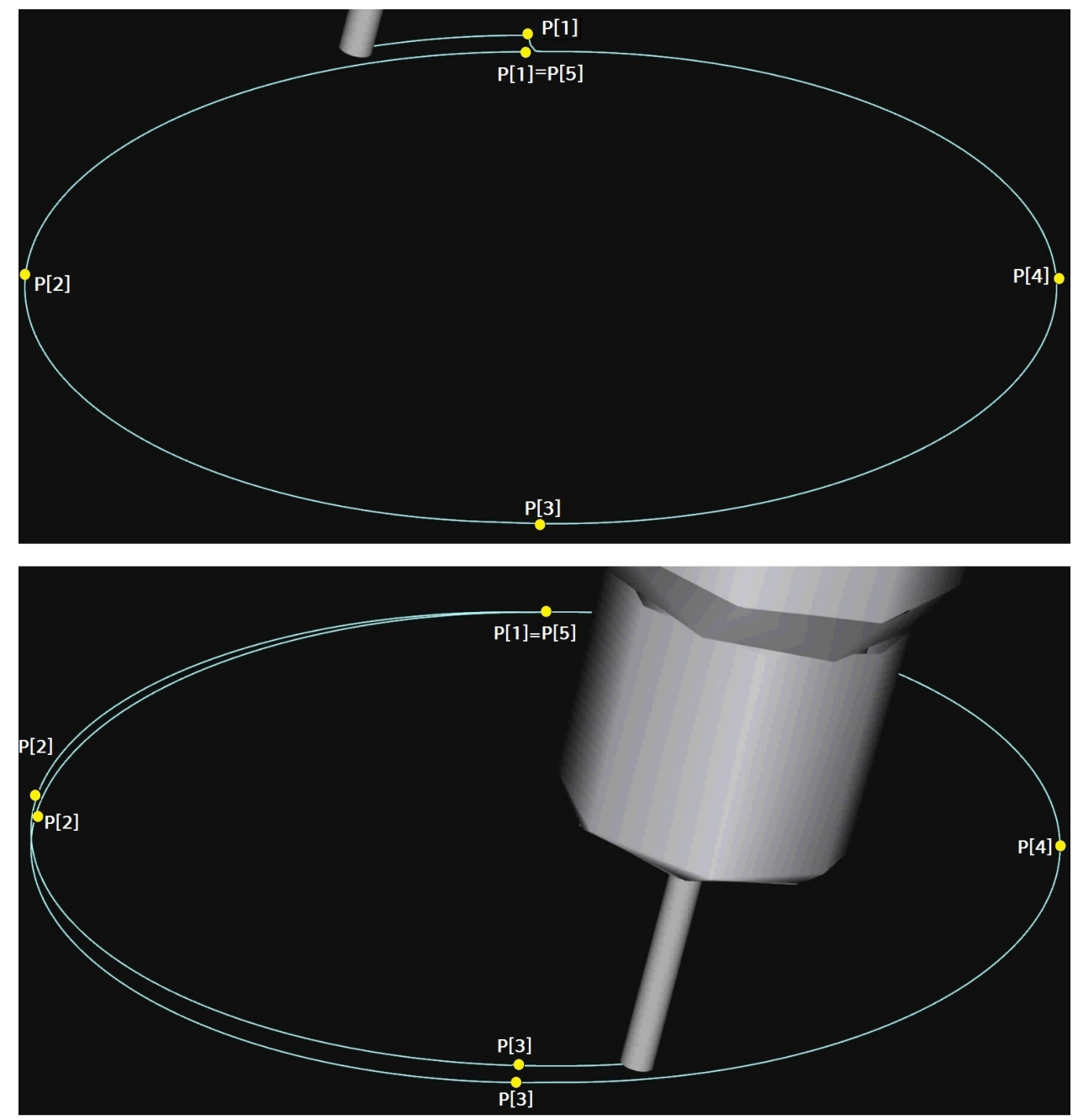

FiguRE 14. Drawing of optimization path. The first image represents the original path. The second image represents an optimized path.

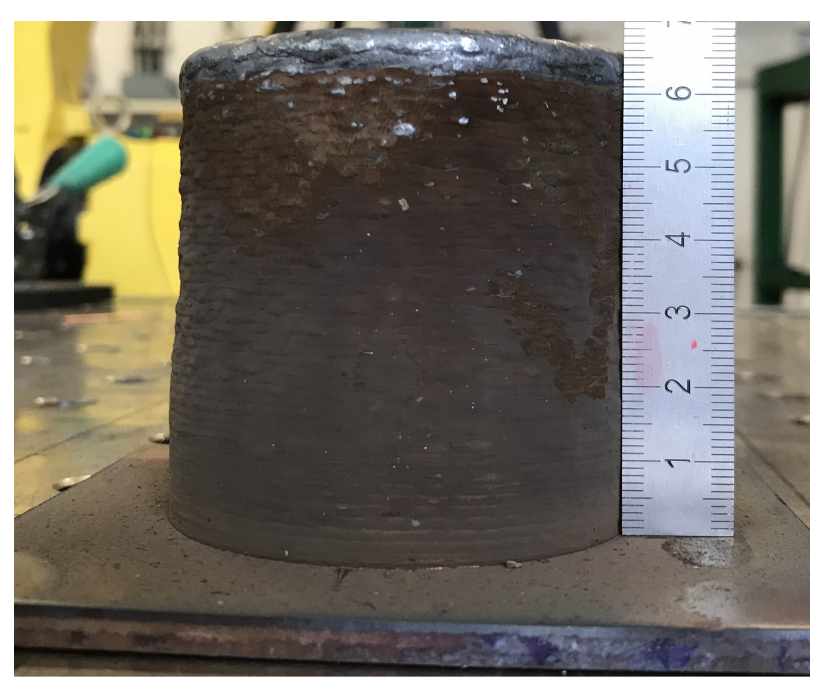

Figure 15. The CMT sample.

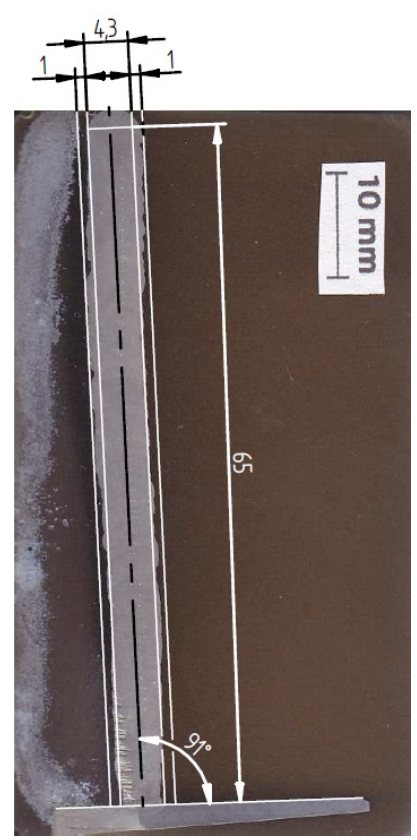

FiguRE 16. EWT and SW parameters for the CMT sample. 
has a great effect on achieving a geometrically stable surface. By appropriately selecting the welding path and the process with the lowest heat input, a predetermined target was achieved. For a CMT sample shown in Figure 15 and Figure 16, the SW parameter values reached a maximum of $1 \mathrm{~mm}$, which confirmed that optimization using the CMT process with a path correction is the right direction for a further research.

\section{ACKNOWLEDGEMENTS}

Thanks to Ing. Štěpán Ježek (DoMT 12133 CTU in Prague, Schäfer - Menk s.r.o.) for providing the filler material for this experiment.

The research was supported by project SGS16/217/OHK2/3T/12. Authors acknowledge support from the EU Operational Programme Research, Development and Education, and from the Center of advanced Aerospace Technology (CZ.02.1.01/0.0/0.0/16_019/0000826), Faculty of Mechanical Engineering, Czech Technical University in Prague.

\section{REFERENCES}

[1] K. Kabeš. Three million industrial robots will be operational in the world (in Czech). Automa 10(23):28 29, 2017.

[2] L. Kolařík, J. Suchánek, M. Kolaříková. Welding method WAAM (in Czech). MM Industrial spectrum 1:60, 2018.
[3] K. Bürgerová. Analysis of defects of a $3 D$ printed metal product (in Czech). Bachelor thesis, Czech Technical University in Prague, Faculty of Mechanical Engineering, 2016.

[4] A. R. McAndrew, M. Alvarez Rosales, P. A. Colegrove, et al. Interpass rolling of Ti-6Al-4V wire + arc additively manufatured features for microstructural refinement. Additive Manufacturing 21:340 - 349, 2018. DOI:10.1016/j.addma.2018.03.006.

[5] Welding Engineering and Laser Processing Centre. Wire + Arc Additive Manufacturing. https://waammat.com/about/waam 2000 - 2018. Accessed: 26 March 2018.

[6] Arcam EBM a GE Additive company. $\mathrm{EBM}^{\circledR}$ in Aerospace: Additive Manufacturing taken to unseen heights.

http://www.arcam.com/solutions/aerospace-ebm/. Accessed: 26 March 2018.

[7] FANUC Czech s.r.o. Intelligent 3-D robot simulation. https://www .fanuc.eu/cz/en/robots/accessories/ roboguide Accessed: 26 March 2018.

[8] Voestalpine Böhler Welding. Most used additional materials for welding, cladding and soldering and preparations for stainless steel.

http://www.bohler-uddeholm.cz/media/ nejpouzivanejsi_materialy_2015_2.pdf Accessed: 26 March 2018. 